\title{
The Practice of Transformational Leadership Style in the Ministry of Labour and Social Development in the Kingdom of Bahrain
}

\author{
Bader Abdulwahab Alkhaja Carl Mark B. Miniano* \\ College of Administrative and Financial Sciences, AMA International University- Bahrain, Building 829, Road \\ 2013, Block 712, PO box 8041, Salmabad, Kingdom of Bahrain
}

\begin{abstract}
Are managers at the Ministry of Labour and Social Development in the Kingdom of Bahrain practicing the Transformational Leadership style? Do managers with longer years of experience practice the four dimensions of transformational leadership more frequently than those with lesser years of experience? These are some of the questions that this study have sought answers to. Specifically, the research tried to determine the frequency at which transformational leadership dimensions such as idealized influence; inspirational motivation; intellectual stimulation; and individualized considerations are being practiced by managers in the said ministry, based on the perceptions of 96 rank and file employees, and 38 managers. It also determined if the frequency of practicing transformational leadership style is significantly related with the years of managerial experience. The study further investigated if managers' perceptions would significantly differ with that of the rank \& file employees. The findings revealed that years' of managerial experience is not significantly related to the frequency of practice of transformational leadership dimensions. It was also found that idealized influence was the most frequently practiced transformational leadership dimension, while inspirational motivation was the least frequently practiced one in the Ministry of Labour and Social Development in the Kingdom of Bahrain.
\end{abstract}

Keywords: Transformational Leadership, Managers, Leadership Dimensions, Government Leaders, Kingdom of Bahrain

DOI: $10.7176 / \mathrm{EJBM} / 11-26-13$

Publication date:September $30^{\text {th }} 2019$

\section{Introduction}

The field of leadership has been widely explored by many, both generally and specifically, in terms of its different types and their applications (e.g. Avolio \& Yammarino, 2002; Buon, 2014; Burns, 1978; Bass \& Riggio, 2006; Gold et al., 2010; Lussier \& Achua, 2010, etc.). Their focus included but was not limited to, the definition of leadership, its importance, the different approaches to it, and the benefits of using such approaches.

Effective leadership is vital in any work environment, as it can be linked to the organization's efficiency and employees' job performance. Leadership is seen as an inspirational process that is concerned with the ability to "influence a group toward a set vision or group of achievable goals" (Hidayat, Rafiki, \& Aldoseri, 2017: 582). It is also linked to the practice of leading others while having a clear vision and providing the knowledge and support to do so. There are different leadership styles and three of the most common styles include transactional, transformational, and laissez-faire. It has been proven that there is a stronger and more positive relationship between transformational leadership and performance, when compared with transactional leadership and performance (Lowe et al., 1996; Dvir, et al., 2002). Transformational leadership encompasses different skills under four dimensions: idealized influence, inspirational motivation, intellectual stimulation, and individualized consideration (Bass \& Avolio, 1993).

In 2008, an all-inclusive vision - Economic Vision 2030 - for the Kingdom of Bahrain was launched to transform the country's economy and provide better opportunities for its citizens by raising the quality of employment to increase the productivity of organizations (Economic Development Board, 2008). The Minister of Electricity and Water Affairs in the Kingdom of Bahrain, Dr. Abdulhusain Mirza, emphasized that transformational leadership has been receiving a lot of attention both internationally and locally. This is because it is an important element of organizations, particularly "in light of challenges and rapid changes in the local, regional and global business environment" (Bahrain News Agency, 2019). He further emphasized that an "effective leader is the person who creates an inspiring vision for the future and motivates people to participate in this vision" (GDNOnline, 2019).

Hidayat, Rafiki, and Aldoseri (2017) conducted a study on implementation of transactional, transformational, and laissez-faire leadership styles in governmental organizations in the Kingdom of Bahrain. They have found out that transactional leadership is the most commonly practiced style of leadership, followed by transformational and laissez-faire styles. One of their recommendations for the government of the Kingdom of Bahrain include adopting a transformational leadership style due to its benefits for both leaders and employees, as established by many (e.g. Buon, 2014; Pradeep \& Prabu, 2011). It is therefore of high relevance to investigate if current leaders in the same 
context possess the characteristics of a transformational leader and, if so, to what extent. Investigating employees' perceptions is also vital, as they are "often in a unique position to judge leadership effectiveness" (Hogan, Curphy, \& Hogan, 1994: 7).

\subsection{Statement of the Problem}

Several existing studies have explored the potential of applying transformational leadership in organizations. If transformational leadership can effectively strengthen job performance and can be a contributing factor to the overall productivity of the organization (Pillai et al., 1999), then it would be useful to develop a set of strategies for leaders to fully utilise or address identified weak areas of transformational leadership practice. As opined by Hidayat, Rafiki, \& Aldoseri (2017), and Dr. Mirza (GDNOnline, 2019), a good number of benefits await the adoption and implementation of transformational leadership in the Kingdom of Bahrain's government sector. Considering that organizations are comprised of leaders and employees, it is crucial to understand both their perceptions in order to develop a set of strategies to ensure its full and effective application.

1.1.1 Research Questions

The following questions were answered in this study:

1. How frequent do managers at the Ministry of Labour and Social Development in Bahrain practice the four dimensions of Transformational Leadership?

2. Which of the leadership dimensions could still be improved as regards its frequency of practice?

3. Is years of managerial experience significantly related to the frequency of transformational leadership practice?

4. Do managers and employees perceptions significantly differ as regards the frequency of transformational leadership practice?

1.1.2 Research Hypothesis

The following hypothesis were tested at 0.05 level of significance:

Ho1: Years of managerial experience is not significantly related to the frequency of practicing Idealized Influence.

Ho2: Years of managerial experience is not significantly related to the frequency of practicing Inspirational Motivation

Ho3: Years of managerial experience is not significantly related to the frequency of practicing Intellectual Stimulation

Ho4: Years of managerial experience is not significantly related to the frequency of practicing Individualized Consideration

Ho5: There is no significant difference between the respondents' perceptions as regards transformational leadership frequency of practice.

1.1.3 Theoretical Framework

This research is anchored on transformational leadership theory, which was conceptualized by James MacGregor Burns in 1978 and was extended by (Bass \& Riggio, 2006). Burns believes that transformational leaders extend their leadership capabilities through stimulating and inspiring their followers to achieve outcomes (Bass \& Riggio, 2006). Avolio and Yammarino (2002) underscored that this type of leadership is vital regardless of the sector and setting it is practiced in. Bass (1999) extended the transformational leadership theory and identified four dimensions, which include idealized influence, inspirational motivation, intellectual stimulation, and individualized consideration (see Figure 1).

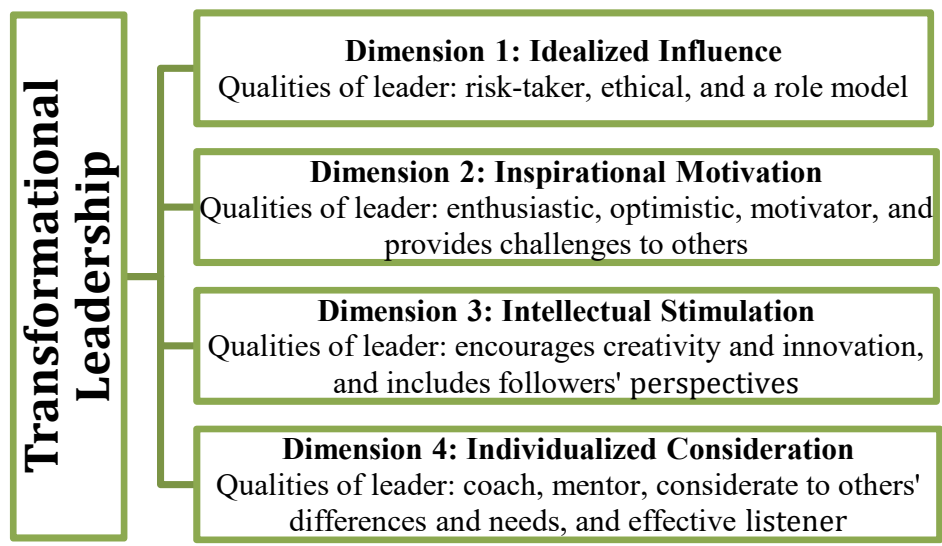

Figure 1

Theoretical Framework (Bass \& Reggio, 2006) 
Bass and Riggio (2006) explain that the first dimension of transformational leadership is idealized influence, where a leader is a risk-taker who demonstrates high standards of ethical and moral conduct and act as a role model to his or her employees. Accordingly, he or she is respected and appreciated, based on two aspects that influence one another: their behaviour and attributed elements. The second dimension is inspirational motivation, where the transformational leader is both enthusiastic and optimistic, motivating and inspiring his or her followers by providing them with a challenge. The third dimension is intellectual stimulation, where the transformational leader encourages creativity and innovation by including the followers' perspectives when tackling issues and searching for solutions. The fourth dimension is individualized consideration, where a leader acts as a coach or mentor while paying close attention to his or her followers' individual differences and needs. Being an effective listener is vital as he or she will have personalized interactions with his or her followers (Bass \& Riggio, 2006).

\section{Methodology}

The study utilized the descriptive research design and quantitative method. Respondents of the study included Thirty-eight (38) managers and Ninety-six (96) rank and file employees from the Ministry of Labour and Social Development in the Kingdom of Bahrain. Two sets of questionnaires were formulated, one for the managers and another for the rank and file employees. Both questionnaires were translated into Arabic, as it is the official language in the governmental sector. The questionnaire was subjected to expert validation and reliability test. Three experts, two from the Ministry of Labour and Social Development, and another expert from the Graduate School of AMA International University- Bahrain, examined the instrument for face and construct validity. The mean value generated was 4.11, which means that the questionnaire's face and construct validity was "Very Good". To ensure the internal consistency of the items in the questionnaire, a reliability test was conducted using the Cronbach Alpha. Table 2.1 shows the result of the reliability test.

Table 2.1

Reliability Test (Cronbach Alpha)

\begin{tabular}{lc}
\multicolumn{1}{c}{ Dimensions of Transformational Leadership } & Cronbach $\boldsymbol{\sigma}$ \\
\hline Dimension 1: Idealized Influence & .922 \\
Dimension 2: Inspirational Motivation & .943 \\
Dimension 3: Intellectual Stimulation & .953 \\
Dimension 4: Individualized Consideration & .936 \\
\hline
\end{tabular}

The alpha coefficient for each of the four items is higher than .70. This suggests that the factors under each dimension have high internal consistency. A five-point Likert scale was used to determine the frequency of transformational leadership practice. The scale was assigned with qualitative interpretation ranging from "Never" to "Always". Responses generated through the survey questionnaires were tallied and statistically processed using the SPSS. The central tendencies in responses were measured through the Weighted Mean., variances were measured through Standard Deviation. Relationship between years of managerial experience and frequency of transformational leadership practice was determined through the use Pearson Product-moment Correlation Coefficient (r), while significant differences between respondents' perceptions was determined through the T-Test.

\section{Literature Review}

It is generally thought that there is no consensus on one definition of leadership (Koech \& Namusonge, 2012) as "there are almost as many definitions of leadership as there are persons who have attempted to define the concept" (Stogdill, 1974: 7). Various individuals perceive leadership differently, as some view it as a combination of traits, or a "measurable and quantifiable property possessed in different amounts by different people" (Jago, 1982: 316). Others perceive it is as observable behaviours, or the actions performed by the leader (Jago, 1982). Jago (1982) stresses that leadership should not be perceived as merely a quality or characteristic that a person has or needs to have, but also as an act which is communicated through interaction between people. Therefore, it is a dynamic process that is both evolving and influential, which includes both the activity and ability of leaders to work with their followers to achieve the organization's objectives (Gold et al., 2010; Jago, 1982; Lussier \& Achua, 2010, Miniano \& Adolfo, 2017).

\subsection{Importance of Leadership}

Leadership is important in any organization considering that the alignment of the work attitudes of members in the organization with the organization's vision can be directly influenced (Hidayat, Rafiki, \& Aldoseri, 2017). This means that leaders need to ensure that their employees' tasks support the organization's goals. In other words, they can contribute to the development of their organization depending on their abilities and aptitudes in addition to being able to influence their employees to achieve the goals of the organization (Riggio, 2009). Furthermore, when organizations are working towards a new strategic direction with new processes, leaders can have an effect on both the speed and efficiency of their implementation (Caldwell et. al., 2008). For instance, they can either strengthen or weaken the implementation of the strategic change. Therefore, the issue of leadership and its importance has 
attracted substantial interest by many, including academics and practitioners (Abdalla, 2013).

\subsection{Leadership Approaches}

Bass and Riggio (2006) emphasized that leaders need to develop leadership skills in their employees, as leadership can appear in any individual and at all levels. There are different approaches that can be implemented by leaders, and one of the most well-known formats to classify and study leadership focuses on three leadership styles: laissezfaire, transactional, and transformational (Koech \& Namusonge, 2012). Laissez-faire leadership style is linked to inefficiency and lack of productivity, since laissez-faire leaders are avoidant; they avoid their responsibilities as superiors or do not intervene with their employees' tasks (Koech \& Namusonge, 2012). However, transactional leaders are those who have a relationship with their employees that focus on a rewards system as well as meeting their physical and security needs. Transformational leaders help their employees achieve their best performance considering that they motivate them and focus not only on their needs, but also on their development. Still, Bass and Riggio (2006) emphasized that although leaders might utilize all the approaches, one approach may be more dominantly used.

\subsection{Transformational Leadership Style}

Due to its focus on intrinsic motivation and positive development of followers, transformational leadership can appear to be more interesting than transactional leadership as the latter can be viewed as a "ccold" social exchange process' (Bass \& Riggio, 2006: xi). Furthermore, transformational leadership "has proven [to be] an effective form of leadership in a variety of settings in many countries" (Bass \& Riggio, 2006: xii). It "has rapidly become the approach of choice for much of the research and application of leadership theory" (Bass \& Riggio, 2006: xi).

Burns (1978: 20) explains that transformational leadership is when "one or more persons engage with others in such a way that leaders and followers raise one another to higher levels of motivation and morality". Four components, or dimensions, of transformational leadership were recognized by Avolio, Bass, and Jung (1997 in Bass \& Riggio, 2006), which include idealized influence, inspirational motivation, intellectual stimulation, and individualized consideration. Determined and confident leaders who visualize a desirable future, share their vision on how to achieve such future as well as set a good example for their followers display both idealized influence and inspirational motivation (Bass, 1999).

Bass and Riggio (2006) explain that the first dimension is idealized influence, where a transformational leader is a risk-taker who demonstrates high standards of ethical and moral conduct and act as a role model to his or her employees. Accordingly, he or she is respected and appreciated based on two aspects that influence one another: their behaviour and attributed elements. The second dimension is inspirational motivation, where the transformational leader is both enthusiastic and optimistic, motivating and inspiring his or her followers by providing them with a challenge. The third dimension is intellectual stimulation, where the transformational leader encourages creativity and innovation by including the followers' perspectives when tackling issues and searching for solutions. The fourth dimension is individualized consideration, where a transformational leader acts as a coach or mentor while paying close attention to his or her followers' individual differences and needs. Being an effective listener is vital as he or she will have personalized interactions with his or her followers (Bass \& Riggio, 2006).

\subsection{Benefits of Using Transformational Leadership}

Transformational leaders have a sense of vision and purpose, believing that people are both dependable, and purposeful, and can uniquely contribute to any organization (Bass \& Avolio 1993: 113). Therefore, they try to develop employees' full potential by letting them take on greater responsibilities (Bass \& Avolio, 1993). This is because one main aspect of transformational leadership is emphasizing employees' development through the evaluation of their current commitments and extension of future responsibilities (Dvir et al., 2002). Employees' personal identification with their leader as well as their social identification with their work unit is positively linked to transformational leadership, with particular emphasis on personal identification (Kark, Shamir, \& Chen, 2003: 253).

\subsection{Transformational Leadership in Organizations}

The significance of leadership in every organization is evident in its direct role in affecting the organization's employees to align their work attitudes with the vision of the organization (Hidayat, Rafiki, \& Aldoseri, 2017: 581). Leadership and the organization's culture can both affect one another; the organization's culture is highly influenced by its leadership, which in turn, influences the development of leadership (Bass \& Avolio, 1993: 112). The organization's culture can be changed by transformational leaders, as they incorporate their creative perceptiveness, determination, instinct, and understanding of the needs of others into understanding the organization's culture and revising its values as well as construct a new vision (Bass \& Avolio, 1993). The characteristics and qualities of transformational leaders guide the organization's culture and is ultimately embraced and implemented by its employees (Bass \& Avolio, 1993). As Avolio and Yammarino (2002 in Bass \& Riggio, 
2006; 2) emphasize, research has established the significance of transformational leadership in all sectors and settings, which can include governmental organizations. This is because governmental organizations have been increasingly prioritizing leadership development programs (Koech \& Namusonge, 2012). Furthermore, it is necessary for leaders in governmental organizations to continually develop their leadership skills as the play a critical role in increasing employee performance (Asencio, 2016).

Different researchers also focused on leadership, particularly transformational leadership, in studies they have conducted (e.g., Abdalla, 2013; Dvir et al., 2002; Hidayat, Rafiki, \& Aldoseri, 2017; Kark, Shamir, \& Chen, 2003; etc.). Some researchers focused on both transactional and transformational leadership styles in specific countries such as Abdalla (2010) who focused on the public sector in the United Arab Emirates and Asencio (2016) who focused on an organization in the public sector in the United States of America. Hidayat, Rafiki, and Aldoseri (2017), on the other hand, aimed to analyse the implementation of three specific leadership styles (transactional, transformational, and laissez-faire) in governmental organizations in the Kingdom of Bahrain. Their findings concluded that transactional leadership is the most commonly practiced style of leadership, followed by transformational and laissez-faire styles of leadership. One of their recommendations for the government of the Kingdom of Bahrain included adopting a transformational leadership style due to its benefits for both leaders and their employees. Accordingly, the current study aims to determine the frequency of the transformational leadership practices that are being implemented by leaders at the Ministry of Labour and Social Development.

To investigate the practice of transformational leadership style, some researchers developed their own questionnaires, such as Asencio (2016) who used a factor analysis of 20 survey items to measure leadership constructs of transformational leadership. Other questionnaires include a Likert-type survey by Dönmez \& Toker (2017) or the TLQ-LGV by Alban-Metcalfe and Alimo-Metcalfe (2000). Dönmez \& Toker (2017) aimed to create a free-access Likert-type survey, which was validated in Turkey with a group of leaders and employees. AlbanMetcalfe and Alimo-Metcalfe (2000), on the other hand, focused their analyses of local government data from the United Kingdom and aimed to make their questionnaire that is comprised of nine scales more gender-inclusive as there are leaders from both genders who work in organizations.

\section{Results and Discussion}

4.1 Frequency of Transformational Leadership Practice in the Ministry of Labour \& Social Development, Kingdom of Bahrain

Table 4.1.1 shows the respondent's perception on transformational leadership practices in the first dimension, idealized influence, as to whether they are confident, powerful, and focus on the higher order ideals and ethics. As shown in the table, managers believe that they always practice this indicator of transformational leadership. In fact, leaders, with a composite mean of 4.51, rated it the highest out of all indicators in all four dimensions

Table 4.1.1

Respondents' Perception on the Practice of Idealized Influence (Indicator 1)

\begin{tabular}{|c|c|c|c|c|c|c|}
\hline \multirow{2}{*}{$\begin{array}{l}\text { Indicator 1: Being confident, } \\
\text { powerful, and focusing on the higher } \\
\text { order ideals and ethics }\end{array}$} & \multicolumn{2}{|c|}{ Managers } & \multicolumn{4}{|c|}{ Rank \& File } \\
\hline & $\bar{x}$ & $\sigma$ & Interpretation & $\bar{x}$ & $\sigma$ & Interpretation \\
\hline Factor 1 & 4.31 & 0.63 & Often & 3.54 & 1.12 & Often \\
\hline Factor 2 & 4.47 & 0.66 & Often & 3.68 & 1.25 & Often \\
\hline Factor 3 & 4.63 & 0.65 & Always & 3.93 & 1.19 & Often \\
\hline Factor 4 & 4.50 & 0.61 & Often & 3.59 & 1.18 & Often \\
\hline Factor 5 & 4.59 & 0.61 & Always & 3.92 & 1.11 & Often \\
\hline Factor 6 & 4.53 & 0.66 & Always & 4.05 & 1.06 & Often \\
\hline Composite Mean & 4.51 & & Always & 3.79 & & Often \\
\hline
\end{tabular}

With the highest weighted mean of 4.63 , managers believe that they always exercise their legitimate power in a responsible manner, not for their own benefit, but for the achievement of the organization's goals. Leaders have to use their power in a responsible manner because "mature moral development" is required (Bass, 1999: 14). Burns (1978) highlights that the "morality of transformational leadership" is fundamental. Accordingly, transformational leaders need to be authentic, have social responsibility, and rise above their own self-interests (Bass \& Riggio, 2006: 14). This is because, as Bass and Riggio (2006) explain, the transformational components of idealized influence can be used "authentically" for a noble cause that will benefit all stakeholders and ensure that followers are both committed and motivated to this cause. Conversely, followers can be manipulated and have an "unhealthy dependence" on their leaders (Bass \& Riggio, 2006: 14).

On the other hand, managers rated their display of a sense of power and confidence the lowest, with a weighted mean of 4.31. Interestingly, it is thought that confidence is a key quality in transformational leaders. Leaders may have difficulty in displaying power and confidence because charisma may be considered a "personal power" (Lee, 2014: 18). Nonetheless, Lee (2014) emphasizes that transformational leadership, in fact, needs 
conceptual clarity because it is unclear how leaders can actually make use of the four dimensions and whether leaders are considered to be transformational if they lack some of the required qualities. In contrast, employees believe that leaders often carry out transformational leadership practices in the idealized influence dimension, with a composite mean of 3.79. This does not correspond to leaders' perceptions, as they believe that they always practice this dimension. With the highest weighted mean of 4.05 , employees believe that their leaders make them feel they are always alert for preventing anything that might lead to the work going astray. Interestingly, Dönmez and Toker (2017: 763) designed this particular questionnaire item as an indicator of transactional leadership factor, but it was "loaded more highly" on the transformational leadership factor by their respondents. Regardless, it supports Hidayat, Rafiki, and Aldoseri's (2017) finding to a certain degree, where they found that transactional leadership is the most commonly applied leadership style in governmental organizations in the Kingdom of Bahrain.

With the lowest weighted mean of 3.54 , the rank \& file believe that their leaders only display a sense of power and confidence often. This corresponds to the leaders' perceptions since this item also had the lowest weighted mean. Kylie (2019) explains that leaders need to avoid comparing themselves to others, as this may draw their attention away from their personal goals and could influence their sense of power and confidence. Leaders need to focus on their current achievements to see what they have accomplished as well as supporting themselves with individuals who support them and have a clear vision of what they would all like to accomplish.

Table 4.1.2

Respondents' Perception on the Practice of Idealized Influence (Indicator 2)

\begin{tabular}{cccccccc}
\hline $\begin{array}{l}\text { Indicator 2: Taking charismatic } \\
\text { actions centred on values, beliefs, }\end{array}$ & $\bar{c}$ & $\mathbf{x}$ & Managers & & & \multicolumn{2}{c}{ Rank \& File } \\
and sense of mission. & 4.31 & 0.68 & Often & 4.07 & 1.17 & Often \\
\hline Factor 1 & 4.31 & 0.58 & Often & 3.74 & 1.09 & Often \\
Factor 2 & 4.56 & 0.66 & Always & 3.89 & 1.06 & Often \\
Factor 3 & 4.50 & 0.66 & Often & 3.74 & 1.19 & Often \\
Factor 4 & 4.42 & & Often & 3.86 & & Often \\
& Composite Mean & & & 4.42 & & & Often \\
\hline
\end{tabular}

In terms of the second indicator of the idealized influence dimension (see Table 4.1.2), which focuses on the factor "leaders taking charismatic actions that are centered on values, beliefs, and a sense of mission", the composite mean received by all items from managers was 4.42 , which is interpreted as "Often". The managers believe that their words and actions are always anchored on generally accepted values and beliefs with the highest weighted mean of 4.56. The lowest weighted mean registered by managers was on the factor "leaders settling problems in the organization, guided by the organization's core values."

The composite mean received by all the factors was 4.42, which is interpreted as "Often". This was consistent with their rating on the first indicator of the idealized influence dimension. However, it needs to be noted that, out of all the indicators in the four dimensions, the rank \& file rated this particular indicator as the highest. The item that had the highest weighted mean was on the factor, "leaders' charismatic behaviour, which influences all employees and creates a good environment for working". Interestingly, it was one of the two factors that had the lowest weighted mean based on the perception of the managers. Sussex (2013) believes that leaders need to engage in meaningful face-to-face interactions with their employees to create a good work environment, since this helps employees feel that they are valuable to their leaders. Additionally, managers believe that their words and actions are always anchored on generally accepted values and beliefs, yet the rank file employees believe that they only "often" do so. This highlights the need for leaders to always ensure that their behaviour in handling employees' emotions and perceptions is based on generally accepted values and beliefs, as it can be of a positive influence on employees' commitment towards organizational change (Loo, Lee, \& Low, 2017).

In contrast, among the rank \& file employees, the two factors that received the lowest weighted mean were related to leaders' emphasizing the importance of having a collective sense of mission and their practices in setting organizational problems. The latter is consistent with the managers' perceptions as it also had the lowest weighted mean in this factor. Nonetheless, resolving problems and having constructive interpersonal conflict management skills are vital in any organization, as it is important for leaders to manage conflicts constructively within their organization (Matjie, 2010). Leaders may be perceived as not being effective in resolving conflicts because there is no consensus as to whether there is a single conflict management style that is effective in all situations. Therefore, leaders need to have a certain level of competence to identify how to resolve each situation in the best way. Furthermore, leaders have to include employees in discussing the impact of the conflict and how to address it in order to understand the issues from different perspectives and be more objective (Mind Tools, 2019). This is because unresolved conflicts may have a negative impact on the work environment (Matjie, 2010) and developing ways to prevent conflicts can reduce the possible long-term effects. 
Table 4.1.3

Respondents' Perception on the Practices of Inspirational Motivation (Indicator 1)

\begin{tabular}{cccccccc}
\hline $\begin{array}{l}\text { Indicator 1: Engaging individuals } \\
\text { through stressing ambitious goals and } \\
\text { viewing the future with optimism. }\end{array}$ & $\overline{\boldsymbol{x}}$ & $\boldsymbol{\sigma}$ & Interpretation & $\overline{\boldsymbol{x}}$ & $\boldsymbol{\sigma}$ & Interpretation \\
\hline Factor 1 & 4.28 & 0.62 & Often & 3.55 & 1.20 & Often \\
Factor 2 & 4.22 & 0.60 & Often & 3.42 & 1.30 & Sometimes \\
Factor 3 & 4.19 & 0.73 & Often & 3.32 & 1.24 & Sometimes \\
Factor 4 & 4.34 & 0.69 & Often & 3.34 & 1.42 & Sometimes \\
Factor 5 & 3.69 & 1.04 & Often & 2.77 & 1.50 & Sometimes \\
Factor 6 & 4.38 & 0.54 & Often & 3.45 & 1.34 & Sometimes \\
Composite Mean & 4.18 & & Often & 3.31 & & Sometimes \\
\hline
\end{tabular}

Table 4.1.3 depicts how managers' perceive their frequency of practicing transformational leadership in the second dimension (inspirational motivation), as to whether they engage employees through putting emphasis on ambitious goals and have an optimistic view of the future. Rated slightly less than the first indicator, the interpretation of the composite mean for managers (4.18) is "Often". Leaders believe that they make their employees feel that what they do is valuable and useful. This received the highest weighted mean of 4.38. On the other hand, managers gave the lowest rating to the factor, "leaders enhance employees' internal motivation by encouraging them through a rewards system". The use of rewards, as reported in the literature (e.g. Dönmez \& Toker, 2017; Hidayat, Rafiki, \& Aldoseri's 2017), is more commonly used with transactional leaders than with transformational leaders. Although it seems that giving rewards is more linked to transactional leadership, rather than transformational leadership, it may still be reasonably effective for transformational leaders to encourage their employees using a rewards system. This could increase their employees' motivation (Bass and Riggio, 2006).

With regard to the rank \& file employees' response (Table 4.1.3), the interpretation of the composite mean (3.31) is consistent with the first indicator. The rank \& file employees believe that their leaders demonstrate insight in their planning for the future, with the highest weighted mean of 3.55. Yet, intriguingly, in agreement with the managers, they also gave the lowest rating to the factor that focuses on how leaders boost employees' internal motivation by using a rewards system to encourage them. However, as Gorschek (2012) clarifies, a well-designed rewards system can enhance employees' internal motivation. Furthermore, the author also emphasized that a strong rewards system needs to have a combination of short-term and long-term motivational tools. The author further argued, that leaders should identify which organizational goals are supported with the rewards system, and which desirable employee actions reinforce these goals. Leaders need to involve employees in decision-making, working with their employees to determine which rewards and appropriate, as this could be an additional source of motivation (Gorschek, 2012).

Table 4.1.4

Respondents' Perception on the Practice of Inspirational Motivation (Indicator 2)

\begin{tabular}{lccccccc}
\hline $\begin{array}{l}\text { Indicator 2: Viewing team } \\
\text { performance and matching it with } \\
\begin{array}{l}\text { organization's expectations as well as } \\
\text { improving overall team efficiency. }\end{array}\end{array}$ & $\overline{\boldsymbol{x}}$ & $\boldsymbol{\sigma}$ & Interpretation & $\overline{\boldsymbol{x}}$ & $\boldsymbol{\sigma}$ & Interpretation \\
\hline Factor 1 & 4.00 & 0.66 & Often & 3.12 & 1.24 & Sometimes \\
Factor 2 & 4.22 & 0.70 & Often & 3.46 & 1.23 & Sometimes \\
Factor 3 & 4.13 & 0.78 & Often & 3.27 & 1.40 & Sometimes \\
Factor4 & 4.28 & 0.72 & Often & 3.49 & 1.30 & Sometimes \\
$\quad$ Composite Mean & 4.16 & & Often & 3.34 & & Sometimes \\
\hline
\end{tabular}

The second lowest weighted mean for employees' was on the factor "leaders setting clear and challenging goals that will stimulate employees' full potential." This was also the second lowest weighted mean according to the managers. Leaders may have difficulty in practicing this item because they are dealing with motivating a group of diverse people, who may have varying degrees of commitment to goals. It needs to be noted that the more employees identify with their leader, the stronger the likelihood of their commitment to achieving goals (Bass and Riggio, 2006).

In terms of the second indicator for inspirational motivation dimension (see Table 4.1.4), concerning leaders viewing team performance and matching it with the governmental organization's expectations along with improving the overall team efficiency, the interpretation of the composite mean of leaders is less than the two indicators in the first dimension. In fact, leaders ranked this indicator the lowest out of all the indicators based on its composite mean of 4.16 .

The item with the highest weighted mean on the other hand was about the leaders helping employees to have a feeling of personal empowerment with respect to work processes. However, the item with the lowest weighted 
mean related to this indicator was about the factor "leaders informing their employees of the short or long-term potential contributions of their work to the organization" This has a weighted mean of 4.00. However, employees are considered as the backbone of an organization, considering that both its accomplishments and shortcomings could depend on them (Boyer, 2019). Therefore, leaders need to provide their employees with periodic briefings about both, which will help them get the bigger picture (Boyer, 2019). This can promote employees' engagement, which will enhance their work performance. Moreover, when employees know what their weak areas are, they can work on them with their leaders (Boyer, 2019). The author further emphasized that leaders need to give their employees the opportunity to contribute to the organization, whether for smaller or bigger tasks. This supports the idea of having a good and robust communication system between leaders and employees (Boyer, 2019).

Table 4.1.5

Respondents' Perception on the Practice of Intellectual Stimulation (Indicator 1)

\begin{tabular}{ccccccc}
\hline Indicator 1: Challenging employees & \multicolumn{4}{c}{ Managers } & \multicolumn{3}{c}{ Rank \& File } \\
to think creatively. & $\overline{\boldsymbol{x}}$ & $\boldsymbol{\sigma}$ & Interpretation & $\overline{\boldsymbol{x}}$ & $\boldsymbol{\sigma}$ & Interpretation \\
\hline Factor 1 & 4.31 & 0.68 & Often & 3.70 & 1.31 & Often \\
Factor 2 & 4.56 & 0.61 & Always & 3.58 & 1.33 & Often \\
Factor 3 & 4.34 & 0.64 & Often & 3.41 & 1.40 & Sometimes \\
Factor 4 & 4.22 & 0.89 & Often & 3.07 & 1.41 & Sometimes \\
Factor 5 & 4.31 & 0.63 & Often & 3.53 & 1.34 & Often \\
& 4.35 & & Often & 3.46 & & Sometimes \\
\hline
\end{tabular}

Rank \& File employees also rated this indicator less than the two indicators in the first dimension. Moreover, the item that received the highest weighted mean from employees is consistent with the managers' perceptions and is related to the leaders helping them have more feelings of personal empowerment. Kark, Shamir, and Chen (2003) explain that the theory of transformational leadership suggests that leaders can contribute to the empowerment of employees. They also emphasized that leaders should help empower employees because it will result in their independence and autonomy, as an empowered employee will have positive self-esteem, is self-motivated, and believes in their personal competence to perform successfully in their work environment.

The item with the lowest weighted mean of 3.12 from the rank and file employees was on the frequency with which leaders inform their employees about their short or long-term potential work contributions to the organization. The success of transformational leaders depends highly on their ongoing communication with their employees and giving them constant feedback about their progress (Gaille, 2018). The author further explains that this is crucial because, when the communication is limited, employees may lose interest in what they are required to do. Bass and Avolio (1993) underscored that leaders who make their employees feel that they all have a unique contribution to make to the organization also display a sense of vision and purpose themselves. This also fosters "a culture of creative change and growth" (Bass \& Avolio, 1993: 113).

With regard to the second indicator of intellectual stimulation, about involving employees in decision-making (see Table 4.1.5), both groups of respondents perceive that leaders often involve employees in making decisions. However, it seems that leaders have difficulty of always giving employees important responsibilities (weighted mean of 4.06). This seems to be consistent with employees' perceptions (weighted mean of 4.12) Nonetheless, giving employees important responsibilities is in fact both needed and important, as delegating responsibilities to employees is one way transformational leaders can empower their employees (Kark, Shamir, \& Chen, 2003).

Leaders who empower their employees are more likely to be trusted by their employees, in comparison to leaders who do not (Lee, Willis, \& Wei Tian, 2018). This is because employees who believe that their leaders are empowering them are likely to be confident and demonstrate initiative. Moreover, leaders need to be more supportive of employees taking initiative in important issues and produce new solutions. Leaders who encourage their employees to generate new ideas support the organization (Lee, Willis, and Wei Tian, 2018).

Table 4.1.6

Respondents' Perception on the Practice of Intellectual Stimulation (Indicator 2)

\begin{tabular}{ccccccc}
\hline $\begin{array}{c}\text { Intellectual Stimulation } \\
\text { Indicator 2: Involving employees in } \\
\text { decision-making. }\end{array}$ & $\overline{\boldsymbol{x}}$ & $\boldsymbol{\sigma}$ & Interpretation & $\overline{\boldsymbol{x}}$ & $\boldsymbol{\sigma}$ & Interpretation \\
\hline Factor 1 & 4.06 & 0.75 & Often & 4.12 & 1.04 & Often \\
Factor 2 & 4.19 & 0.58 & Often & 3.47 & 1.25 & Sometimes \\
Factor 3 & 4.28 & 0.72 & Often & 3.42 & 1.23 & Sometimes \\
Factor 4 & 4.06 & 0.83 & Often & 3.42 & 1.34 & Sometimes \\
Factor 5 & 4.09 & 0.72 & Often & 3.59 & 1.29 & Often \\
Factor 6 & 4.28 & 0.67 & Often & 3.38 & 1.31 & Sometimes \\
$\quad$ Composite Mean & 4.16 & & Often & 3.57 & & Often \\
\hline
\end{tabular}


However, as explained by Lee, Willis, and Wei Tian (2018), some leaders may find it difficult to always delegate responsibilities because they might believe that their employees may interpret it as an attempt by them to avoid completing the tasks themselves. Furthermore, the authors further argued that giving additional responsibilities to employees may result in leaders burdening their employees and increasing the level of job stress, which may have a negative effect on employees' routine performance. This indicates that leaders need to be careful and ensure that they are not adding excessive pressure, which suggests the need for leaders to understand their employees' expectations. When the expectations of both leaders and employees are aligned, employees will feel more empowered.

Table 4.1. 6 exhibits the respondents' perception on the dimension individualized consideration, as to whether leaders care for employees' individual needs. Both managers and rank and file employees perceive that leaders "often" follow these principles (composite mean is 4.26 and 3.58 respectively). However, employees believe that their leaders only support them and help them with their personal problems "sometimes". Furthermore, they claimed that leaders only sometimes make sure that their employees have good working conditions to maintain job satisfaction. This suggests that leaders need to consider supporting their employees more in terms of their personal problems and ensure that the working conditions are good to ensure job satisfaction.

The item that received the highest weighted mean from both managers and rank \& file employees was about the factor "leaders being considerate towards their employees' needs and treating them as individuals, rather than just team members". Peters (2015) highlights that there are many perceived benefits when leaders and employees have positive relationships in the organization, as they can aid in transforming it and improve in several aspects. Aspects include improved loyalty, productivity, engagement, and employee retention. This is because, when employees work closely together in an organization, various issues may arise. Being considerate towards employees' needs and focusing on fostering relationships can help in working through issues and conflicts, as employees recognize that their voices are both heard and respected. In addition, Peters (2015) also explains that the leader-employee relationship can be a starting point for developing an improved organizational culture as a whole, which will increase employees' satisfaction. Moreover, he highlights that this will result in a "culture of collaboration" and mutual motivation, which will increase employees' efficiency.

Table 4.1.7

Respondents' Perceptions on the Practice of Individualized Consideration (Indicator 1)

\begin{tabular}{ccccccc}
\hline $\begin{array}{c}\text { Indicator 1: Caring for employees' } \\
\text { individual needs. }\end{array}$ & $\overline{\boldsymbol{x}}$ & $\boldsymbol{\sigma}$ & Interpretation & $\overline{\boldsymbol{x}}$ & \multicolumn{2}{c}{$\begin{array}{c}\text { Rank \& File } \\
\text { Interpretation }\end{array}$} \\
\hline Factor 1 & 4.44 & 0.61 & Often & 3.86 & 1.15 & Often \\
Factor 2 & 4.16 & 0.83 & Often & 3.03 & 1.30 & Sometimes \\
Factor 3 & 4.28 & 0.84 & Often & 3.72 & 1.28 & Often \\
Factor 4 & 4.28 & 0.62 & Often & 3.84 & 1.15 & Often \\
Factor 5 & 4.16 & 0.62 & Often & 3.57 & 1.25 & Often \\
Factor 6 & 4.22 & 0.60 & Often & 3.47 & 1.32 & Sometimes \\
Composite Mean & 4.26 & & Often & 3.58 & & Often \\
\hline
\end{tabular}

On the other hand, the item with the lowest weighted mean, as rated by both groups of respondents, was about the factor " leaders supporting and helping employees with their personal problems." It is thought-provoking that employees think leaders are weak at this as it could determine who is an authentic transformational leader. This is because authentic transformational leaders are genuinely concerned with their employees' desires as well as their needs (Bass \& Riggio, 2006). They also care about their employees' individual development where employees are treated as "ends [and] not just means" (Bass \& Riggio, 2006: 14). Leaders have a moral responsibility to take care of their employees and counsel them about personal problems.

Table 4.1.8 shows the second indicator of the individualized consideration dimension, the composite mean of the rank \& file employees' responses to this indicator is interestingly the lowest out of all the indicators. This suggests the need for leaders to support their employees' professional development. Abdalla (2010) found that this dimension is indicative of a direct relationship between leaders and employees and has the strongest positive correlation with the performance of employees as well as their affective commitment.

In terms of the managers' response, the lowest mean of all the items in this indicator was on the factor "planning trainings for areas employees need to improve in". This is consistent with the employees' response, (mean 3.03), which indicates that leaders need to plan trainings for areas they need to improve in. Planning trainings may be an area where leaders in the Ministry of Labour and Social Development may need to be work on. Managers may not practicing this dimension to a higher frequency because there is a specific section within the directorate of Human Resources in the Ministry of Labour and Social Development that is in-charge of training and employees' development. Leaders have the responsibility to determine their employees' training needs and communicate with that section about these training needs. 
Table 4.1.8

Respondents Perception on the Practice of Individualized Consideration (Indicator 2)

\begin{tabular}{|c|c|c|c|c|c|c|}
\hline \multirow{2}{*}{$\begin{array}{l}\text { Indicator 2: Supporting employees' } \\
\text { professional development. }\end{array}$} & \multicolumn{3}{|c|}{ Managers } & \multicolumn{3}{|c|}{ Rank \& File } \\
\hline & $\bar{x}$ & $\boldsymbol{\sigma}$ & Interpretation & $\bar{x}$ & $\sigma$ & Interpretation \\
\hline 1. Factor 1 & 4.38 & 0.70 & Often & 3.26 & 1.50 & Sometimes \\
\hline 2. Factor 2 & 3.88 & 0.78 & Often & 3.03 & 1.47 & Sometimes \\
\hline 3. Factor 3 & 4.13 & 0.70 & Often & 3.23 & 1.51 & Sometimes \\
\hline 4. Factor 4 & 4.28 & 0.62 & Often & 3.27 & 1.49 & Sometimes \\
\hline 5. Factor 5 & 4.47 & 0.56 & Often & 3.51 & 1.40 & Often \\
\hline Composite Mean & 4.23 & & Often & 3.26 & & Sometimes \\
\hline
\end{tabular}

Training employees is vital because it helps expand the knowledge base of employees, strengthen any weak skills, improve their performance, and ensure that employees have consistent experience and background knowledge (Frost, 2019). If leaders want to plan effective training programs themselves, then they need to focus on four elements of planning effective training programs. Berger (2018) stresses that one of these elements includes ensuring that employees get "micro" or "bite-size segments" of training that can be immediately practiced and easily retained. Another element is ensuring that training programs are mobile, or both accessible and convenient for employees, so they can access them whenever and wherever needed. Other elements of successful training programs include ensuring that they are memorable and measurable, where leaders can keep track of the effect of these programs on their employees.

4.2 Dimensions of Transformational Leadership that could still be Enhanced As regard Frequency of Practice. Table 4.2.1

Ranking of the Frequency of Transformational Leadership Practice

\begin{tabular}{lcccc}
\multicolumn{1}{c}{ Dimensions } & $\begin{array}{c}\text { Managers } \\
\text { Composite Mean }\end{array}$ & Rank & Composite Mean & Rank \\
\hline Idealized Influence & 4.47 & 1 & 3.83 & 1 \\
Inspirational Motivation & 4.17 & 4 & 3.33 & 4 \\
Intellectual Stimulation & 4.26 & 2 & 3.52 & 2 \\
Individualized Consideration & 4.25 & 3 & 3.42 & 3 \\
\hline
\end{tabular}

As shown in Table 4.2.1, the composite mean for both indicators in each dimension were ranked from highest to lowest. It can be inferred that both leaders and employees believe that the leaders' transformational leadership practices in the idealized influence dimension is practiced more frequently, followed by intellectual stimulation, individualized consideration, and inspirational motivation dimensions. Therefore, it can be concluded that leaders may need to improve their frequency of practice in the individualized consideration dimension.

\subsection{Relationship between Years of Managerial Experience and Frequency of Transformational Leadership} Practice

Table 4.3.1

Correlations between years of managerial experience and frequency of practicing transformational leadership dimensions

\begin{tabular}{llcc}
\hline Managerial Experience & Transformational Leadership Dimensions & R- Statistics & Sig. (2-tailed) \\
\hline Years of Experience & Idealized Influence & .234 & .198 \\
Years of Experience & Inspirational Motivation & .255 & .160 \\
Years of Experience & Intellectual Stimulation & .131 & .475 \\
Years of Experience & Individualized Consideration & .055 & .766 \\
\hline
\end{tabular}

**Correlation is significant the 0.01 level (2-tailed)

A Pearson Product-moment Correlation Coefficient (r) was used to assess the relationship between years of managerial experience and the frequency of practicing the four dimensions of transformational leadership. Table 4.3.1 shows that the years' of managerial experience is not significantly related to the frequency of practicing idealized influence $(\mathrm{r}=.234, p=.198)$; inspirational motivation $(\mathrm{r}=255, \mathrm{p}=.160)$; intellectual simulation $(\mathrm{r}=.131$, $p=.475$ ), and individualized consideration ( $\mathrm{r}=.055, \mathrm{p}=0.766$ ). This means that longer years' of managerial experience does not relate to the frequency that managers practice transformational leadership dimensions. A new manager or a more experienced one can both practice transformational leadership dimensions to whatever frequency This indicates that even if managers have less years of experience, they could practice the dimensions to a higher frequency. On the other hand, it should not be readily accepted that managers with more years of experience always practice the transformational leadership dimensions. 


\subsection{Differences in Respondents Perception}

Table 4.4.1

Paired Samples T-Test

\begin{tabular}{lcccccc}
\hline Respondents & $\overline{\boldsymbol{x}}$ & $\boldsymbol{\sigma}$ & Correlation & $\mathbf{d f}$ & t-statistics & Sig.(2-tailed) \\
\hline Managers & 4.309 & .4230 & .322 & 37 & .419 & .001 \\
Rank \& File & 3.538 & .8404 & & &
\end{tabular}

A paired sample t-test was conducted to compare the perceptions of the managers and rank \& file employees regarding the frequency by which the managers are practicing the different dimensions of transformational leadership style. Table 4.4.1 shows that the managers and rank \& file employees' perceptions are weakly and positively correlated $(\mathrm{r}=22, p<0.001)$. It also shows that there was a significant difeerence in the perception of managers $(\bar{x}=4.309, \sigma=.4230)$ and the rank \& file employees $(\bar{x}=3.538, \sigma=.4230)$, conditions $\mathrm{t}(37)=.419$, $p=.001$. This means that although managers in the Ministry of Labour and Social Development are practicing the four dimensions of transformational leadership, employees may not have observed some managers practicing the same. On the other hand, leaders may believe that they are practicing transformational leadership at a higher frequency when they are not in reality, as perceived by the rank and file employees. The discrepancy in the perceptions between managers and rank \& file employees suggest that there is a need for all to have a clearer picture of what transformational leadership practices entail.

\section{Conclusion}

The empirical findings have shown that the managers' years of leadership experience has no significant relationship with the frequency that they practice the four transformational leadership dimensions. However, it is concluded, that there is a significant difference between the perceptions of managers and rank \& file employees with regards to the frequency with which managers are applying the transformational leadership principles.

It is further concluded that applying the four dimensions of transformational leadership style more frequently, has several advantages to an organization as highly emphasized by various literatures. Furthermore, the leaders in the Ministry of Labour and Social Development do utilize transformational leadership style as evidenced by the perceptions of the managers and rank \& file employees, specifically the practices under idealized influence. In fact, the principles of the two dimensions that the leaders were practicing more frequently were the idealized influence and intellectual stimulation dimension. On the other hand, leaders need to practice the principles in the inspirational motivation and individualized consideration dimensions more frequently as it emerged to be practiced less frequently. Leaders need to focus more on the dimensions of inspirational motivation, as it was the least frequently practiced dimension.

Leaders need to consciously emphasize the different dimensions of transformational leadership they are practicing, as employees may not be aware of all of them. This is because, in several instances, some of the employees perceived the leaders' directions and strategies differently and, in some cases, negatively. To sum up, managers in the Ministry of Labour and Social Development who more frequently practice the transformational leadership style in its four dimensions were better perceived by their employees than managers who do it less frequently.

\section{References}

Abdalla, H. (2010). The influence of transformational and transactional leadership on employee performance and organizational commitment: A case study in the UAE public sector. (Unpublished master's thesis). The British University in Dubai, Dubai, UAE.

Abdalla, L. (2013). An exploration of transformational leadership preferences among women sports leaders in the Kingdom of Bahrain. Physical Culture and Sport Studies and Research, LVII, 29-32.

Alban-Metcalfe, R. \& Alimo-Metcalfe, B. (2000). The transformational leadership questionnaire (TLQ-LGV): A convergent and discriminant validation study. Leadership \& Organization Development Journal, 21(6), 280296.

Asencio, H. (2016). Leadership, trust and organizational performance in the public sector. Transylvanian Review of Administrative Sciences, Special Issue, 5-22.

Avolio, B. J., Bass, B. M., \& Jung, D. I. (1997). Replicated confirmatory factor analyses of the Multifactor Leadership questionnaire. Binghamton, NY: Center for Leadership Studies, Binghamton University.

Avolio, B. J., \& Yammarino, F. J. (Eds.). (2002). Transformational and charismatic leadership: The road ahead. Boston: JAI.

Bahrain News Agency (2019). Electricity Minister opens leadership conference. Manama: 
https://www.bna.bh/en/news?cms=q8FmFJgiscL2fwIzON1\%2BDptwJCofIkHkzfKks5fyu6Y\%3D

Bass, B. (1995). Theory of transformational leadership redux. Leadership Quarterly, 6, 463-478.

Bass, B. (1999). Two decades of research and development in transformational leadership. European Journal of Work and Organizational Psychology, 8(1), 9-32.

Bass, B., \& Avolio, B. (1993). Improving organizational effectiveness through transformational leadership. Thousand Oaks: Sage Publications.

Bass, B. \& Riggio, R. (2006). Transformational leadership (2nd ed.). New Jersey: Lawrence Erlbaum Associates Publishers.

Berger, D. (2018). Training employees is a must for leaders. Retrieved from https://www.nafcu.org/bergerleadership-blog/training-employees-must-leaders

Boyer, S. (2019). How to engage employees: A complete guide for managers. Retrieved from https://www.nutcache.com/blog/how-to-engage-employees/

Buon, T. (2014). The leadership coach, Hodder \& Stoughton.

Burns, J. (1978). Leadership. New York: Harper \& Row.

Caldwell, D., Chatman, J., O'Reilly, C., Ormiston, M., \& Lapiz, M. (2008). Implementing strategic change in a health care system. Health Care Management Review, 33(2), 124-133.

DeMers, J. (2015). 7 Strategies for delegating better and getting more done. Retrieved from https://www.inc.com/jayson-demers/7-strategies-to-delegate-better-and-get-more-done.html

Dönmez, S., \& Toker, Y. (2017). Construction of a Likert-type transformational leadership scale. DTCF Dergisi, 57(2), 753-775.

Dvir, T, Eden, D., Avolio, B., \& Shamir, B. Avollo, Shamir, (2017). Impact of transformational leadership on follower development and performance: A field experiment, Academy of Management Journal, 45(4), 735744.

Frost, S. (2019). The importance of training \& development in the workplace. Retrieved from https://smallbusiness.chron.com/importance-training-development-workplace-10321.html

Gaille, B. (2018). 22 Advantages and disadvantages of transformational leadership. Retrieved from https://brandongaille.com/22-advantages-and-disadvantages-of-transformational-leadership/

GDNOnline. (2019). More than 200 people participate in key leadership conference. Retrieved from http://www.gdnonline.com/Details/522224

Gold, J., Thorpe, R. \& Mumford, A. (2010). Handbook of leadership and management development. Aldershot: Gower Publishing Company.

Gorschek, T. (2012). Reward and motivation: Enabling effective and efficient professionals. Presentation, Blekinge Institute of Technology.

Hidayat, S., Rafiki, A. \& Aldoseri, M. (2017). Application of leadership style in government organizations: A survey in the Kingdom of Bahrain. International Journal of Islamic and Middle Eastern Finance and Management, 10(4), 581-594. https://doi.org/10.1108/IMEFM-06-2015-0075

Hogan, R., Curphy, G., \& Hogan, J. (1994). What we know about leadership: Effectiveness and personality. American Psychologist, 49(6), 493-504. doi: 10.1037//0003-066x.49.6.493

Jago, A. G. (1982) Leadership: Perspectives in theory and research. Management Science, 28(3), 315-336.

Jaques, E., \& Clement, S. D. (1994). Executive leadership: a practical guide to managing complexity. Cambridge: Carson-Hall.

Juneja, P. (2019). Role of employees in organization culture. Retrieved from https://www.managementstudyguide.com/role-of-employees-in-organization-culture.htm

Kappel, M. (2018). How to encourage employee involvement in decision making. Retrieved from https://www.forbes.com/sites/mikekappel/2018/04/04/how-to-encourage-employee-involvement-indecision-making/\#333954e96561

Karaca, H. (2010). The effects of transformational leadership on employees' perceived leadership effectiveness in Public Organizations Federal Emergency Management Agency Case. (Unpublished doctoral dissertation). University of Central Florida, FL, USA.

Kark, R., Shamir, B., \& Chen, G. (2003). The two faces of transformational leadership: Empowerment and dependency. Journal of Applied Psychology, 88(2), 246-255.

Koech, P. M. \& Namusonge, G. S. (2012) The effect of leadership styles on organizational performance at State Corporations in Kenya. International Journal of Business and Commerce. 2(1), 1-12.

Kylie, C. (2019). 5 strategies to boost your confidence as a leader. Retrieved from https://www.allbusiness.com/5strategies-boost-confidence-leader-19493-1.html/2

Lee, A., Willis, S., \& Wei Tian, A. (2018). When empowering employees works, and when it doesn't. Retrieved from https://hbr.org/2018/03/when-empowering-employees-works-and-when-it-doesnt

Lee, M. (2014). Transformational leadership: Is it time for a recall?. International Journal of Management and Applied Research, 1(1), 17-29. doi: 10.18646/2056.11.14-002 
Lewis, E., Boston, D., \& Peterson, S. (2017). A global perspective of transformational leadership and organizational development. Journal of Research Initiatives, 2(3), 1-6.

Loo, J., Lee, P., \& Low, A. (2017). Impact of transformational leadership and the mediating effect of employees' perception of organizational change on affective, normative and continuance commitment. Journal of Business and Social Review in Emerging Economies, 3(2), 185-197.

Lowe, K., Kroeck, K., \& Sivasubramaniam, N. (1996). Effectiveness correlates of transformational and transactional leadership: A meta-analytic review of the MLQ literature. The Leadership Quarterly, 7(3), 385425.

Lussier, R. N. \& Achua, C. F. (2010). Leadership: Theory, application \& skill development (6th edn). Boston: Cengage Learning

Matjie, M. (2010). The relationship between transformational leadership, emotional competence and conflict management skills of managers in the public sector. (Unpublished master's thesis). University of Limpopo, Limpopo, South Africa.

Mind Tools. (2019). Resolving team conflict: Building stronger teams by facing your differences. Retrieved from https://www.mindtools.com/pages/article/newTMM_79.htm

Miniano, C.M. \& Adolfo, M. (2018). Leadership awakening, metamorphosis and transcendence: Insights from the leadership journey of twelve former presidents of a National Human Resource Managers' Association in the Philippines. The International Journal of Business and Management, 6(4), 329-326.

Moey, S. (2016). A conceptual framework of transformational and transactional leadership on nurse educators job satisfaction. International Journal of Social Science and Humanities Research, 4(1), 596-605.

Newcomer, L. (2016). Think outside the box: 9 ways to unleash workplace creativity - Quill.com Blog. Retrieved from https://www.quill.com/blog/workplace-culture/think-outside-the-box-9-ways-to-unleash-workplacecreativity.html

O'Hara, C. (2018). How to manage an employee who's having a personal crisis. Retrieved from https://hbr.org/2018/07/how-to-manage-an-employee-whos-having-a-personal-crisis

Peters, C. (2015). 3 Benefits of strong employer-employee relationships to be thankful for. Retrieved from http://blog.xanedu.com/blog/3-benefits-of-strong-employer-employee-relationships-to-be-thankful-for

Pickering, A. (1995). The mangle of practice: Time, agency, \& science. Chicago and London: University of Chicago Press.

Pillai, R., Schriesheim, C. A., \& Williams, E. S. (1999). Fairness perceptions and trust as mediators for transformational and transactional leadership: A two-sample study. Journal of Management, 25, 897-933.

Pradeep, D. D \& Prabhu, N. R. V. (2011). The relationship between effective leadership and employee performance. International Conference on Advancements in Information Technology with Workshop of ICBMG IPCSIT Vol. 20. (pp. 198-207). Singapore: IACSIT Press.

Riggio, R.E. (2009). Are you a transformational leader? Psychology Today. Retrieved from http://blogs.psychologytoday.com/blog/cutting-edge-leadership/200903/are-you-transformational-leader

Salkind, N. (2010). Encyclopedia of research design. Los Angeles: SAGE.

Smith, R. (2015). Advantages and barriers to transformational leadership implementation in a Scientific Laboratory. (Unpublished doctoral dissertation). Walden University, MN, USA.

Stogdill, R. M. (1974). Handbook of leadership. New York: The Free Press.

Sussex, T. (2013). 5 ways to create a positive work environment. Retrieved from https://www.liquidplanner.com/blog/5-ways-to-create-a-positive-work-environment/

Trochim, W. M. (2006). The research methods knowledge base. Retrieved from https://socialresearchmethods.net/kb/

Ward, S. (2019). Leadership definition: What is leadership? And can you learn to be a good leader? The Balance Small Business. Retrieved from https://www.thebalancesmb.com/leadership-definition-2948275 